\title{
Visual discrimination learning by the visually-naive split-brain cat '
}

ROY W. PICKENS 2 AND ROGER L. KELLEY

AUBURN UNIVERSITY

Visual-discrimination leaming rates of the separate cerebral hemispheres were compared in dark-reared and normallyreared split-brain cats. No significant difference was found in the hemispherical learning rates of the dark-reared Ss; a significant difference was found in one of the normallyreared Ss. Performance with one hemisphere on a given trial was found to have no significant effect on the performance of the opposite hemisphere on the following trial.

Adult cats with mid-line section of the optic chiasma and corpus callosum are unable to exhibit with one eye a visual-pattern discrimination learned with the other eye (Myers \& Sperry, 1953). While no essential difference has been found between the learning rates of the two hemispheres of visually-experienced splitbrain animals (Sperry, Stamm, \& Miner, 1956), no such comparison has been made with animals in the process of developing visual perception. The present experiment compares the rate at which visualpattern discrimination is learned by the two hemispheres of the visually-naive animal.

Subjects

The Ss were four male cats of mixed breed, two dark-reared experimental animals and two normallyreared control animals. The experimental Ss were housed from birth in a light-proof room, and were about $6 \mathrm{mo}$. old at surgery. The control Ss were housed in a normally-lighted room, and were similar to the experimental Ss in age and weight at surgery. The Ss' daily diet was composed of tap water and commercial cat food, with weekly supplements of $1 / 2$ pt. milk and $1 / 4 \mathrm{lb}$. pork liver.

surgery

Following exposure of the cortex, the superior sagittal sinus was gently reflected, and a neurological scalpel was stereotaxically guided to make a midline transection of the corpus callosum, the anterior commissure, and the optic chiasma. Following training, all Ss were sacrificed, and the brains removed and examined for completeness of the chiasmatic, commissural, and callosal sections.

Apparatus

The apparatus was a modified Yerkes discrimination chamber, approximately 70 in. long $x 30$ in. wide $x$ 15 in. high, constructed from plywood and painted flat black. Two stimulus doors, 8-1/2 in. wide $x 11$ in. high, were located at one end of the chamber, and a starting box, approximately 5 in. wide $x 25$ in. long, was located at the other. The stimulus doors were separated by a 17 in. long partition, and were illuminated by a 100-W frosted bulb with reflector.
The discriminative stimuli were $X$ and $O$, drawn with a black commercial marking pen on white bond paper and enclosed in clear acetate envelopes. The height and width of each figure was 4 in. Brightness discrimination, which is generally not affected by the split-brain preparation (Meikle \& Sechzer, 1960), was controlled by the random use of two pairs of stimulus patterns, one pair with the $X$ having a slightly greater surface area than the $O$ and the other pair with the $O$ having a slightly greater surface area than the $X$.

\section{Procedure}

Training of Ss began 4-6 weeks after surgery. The procedure consisted of alternately training the left and right cerebral hemispheres of each $S$ to criterion on a visual-pattern discrimination task. Each hemisphere was trained independent of the other by restricting visual input only to that hemisphere being trained on a given trial. Before the start of formal training Ss were pretrained to push open the stimulus doors of the discrimination chamber to obtain their daily supply of food, with equal periods of training given each hemisphere.

At the start of formal training the discriminative stimuli, $X$ and $O$, were attached to the stimulus doors, and by pushing open the door containing the $X$ pattern the $S$ was rewarded with a small amount of food. The door containing the $O$ pattern was always locked, and a door bell was sounded when $S$ entered the alley containing this pattern. The daily amount of food was calculated to maintain $S$ at about $80 \%$ of his original body weight. The left-right arrangement of the $\mathrm{X}$ and $O$ patterns on successive trials was determined independently for each hemisphere by separate Gellerman series.

The daily training schedule consisted of 40 alternating trials, 20 per hemisphere, except during the last seven days of training when two 40-trial sessions were given each day. The experimental Ss were returned to darkness between training sessions for the first 120 trials; after that time they were exposed to light $24 \mathrm{hr}$. per day. During training, correction trials were given and one error was recorded when one or more entrances were made into the incorrect alley on a given trial. Responses were recorded in groups of 10 trials, with learning criterion set at 18 or more correct responses in two successive 10-trial groups. When learning criterion was reached for one hemisphere, the opposite hemisphere was trained alone until it met criterion, and then both hemispheres were over-trained for 60 trials. 

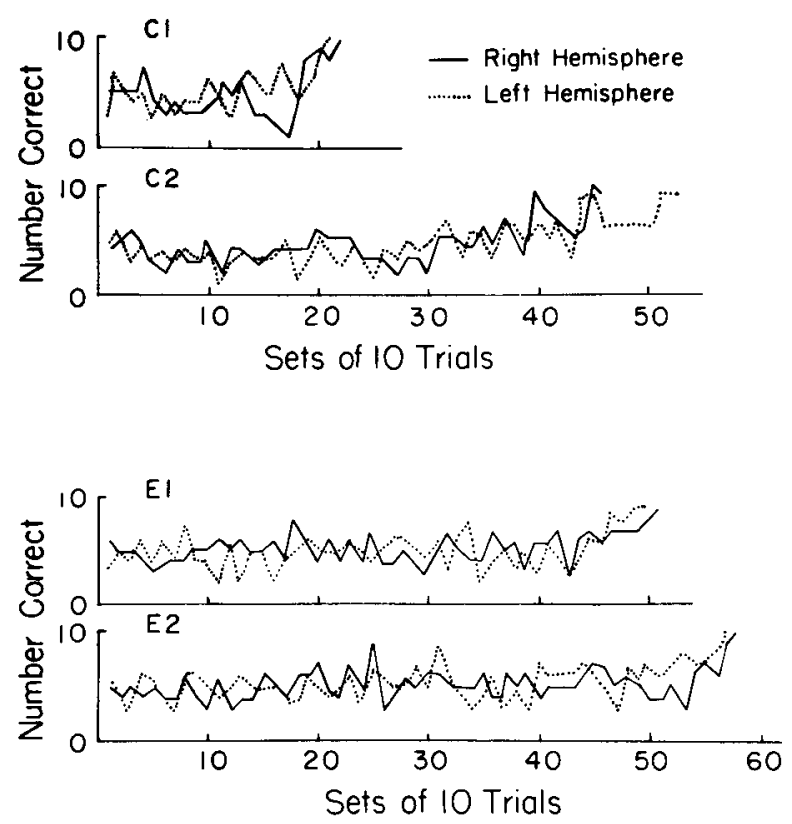

Fig. 1. Leaming curves of left and right hemispheres for all animals.

\section{Results}

Behavioral. Figure 1 shows the learning curves of the left and right cerebral hemispheres for the experimental animals, E1 and E2, and for the control animals, C1 and C2. To determine whether the obtained differences were statistically significant, the data for each $S$ were arranged in blocks of $\mathbf{5 0}$ trials. In cases where the learning criterion was reached with one hemisphere before being reached with the other, or, where the criterion was reached with both hemispheres before a block of 50 trials was complete, the remainder of the block was completed by using over-training trials. Analyses of variance found no significant difference in the learning rates of the hemispheres of E1, E2, and C1. The difference for C2, however, was significant ( $p<.05)$. A Pearson product-moment correlation coefficient between the performance of the two hemispheres of each $S$ was +.67 for $E 1,+.80$ for $E 2,+.87$ for $\mathrm{C1}$, and +.82 for $\mathrm{C2}$. No significant difference was found between the mean correlations for the experimental and control Ss.

To determine whether performance by one hemisphere on a given trial influenced the performance of the opposite hemisphere on the following trial, a Chi-square test was computed in which the number of correct and incorrect responses for each hemisphere on one trial were grouped according to correct or incorrect responses by the other hemisphere on the following trial. This test was performed on each $S$ ceparately, on the experimental and control Ss separately, and on all Ss combined. No significant response pattern was found.

Anatomical. Examination of the brains showed com- plete section of the corpus callosum and anterior commissure in all Ss, and complete section of the optic chiasma in E1, C1, and C2. A small bundle of fibers in the optic chiasma of E2 escaped transection. This bundle was less than $1 \mathrm{~mm}$ in diameter and was located at the base of the optic chiasma, midway between the anterior and posterior segments.

\section{Discussion}

The results of this study suggest that no essential difference exists in rate of formation of a simple visual-pattern discrimination by the separate cerebral hemispheres of the visually-naive cat. The failure to find a significant difference in the learning rates of the two hemispheres of one of the normally-reared cats agrees substantially with other studies (Sperry, Stamm, \& Miner, 1956). In the present study, however, a significant difference was found in the hemispheric learning rates of one normally-reared animal. This discrepancy cannot be explained.

Although normal cats show immediate transfer of monocularly-learned visual-pattern discriminations, cats whose visual experience through one eye has been previously restricted to diffuse light do not exhibit interocular habit transfer (Riesen, Kurke, \& Mellinger, 1953). In fact, some stimulation of both eyes by patterned light has been found necessary before transfer will occur (Riesen \& Mellinger, 1956). Thus, it seems probable that the cerebral hemispheres of the split-brain cat with restricted visual-pattern stimulation would be even more independent than the hemispheres of the normal split-brain animal, as slight improvements in the learning rate of one hemisphere in the visually-restricted animal would be less likely to be indirectly transferred to the opposite hemisphere.

\section{References}

Meikle, T. H., \& Sechzer, J. A. Interocular transfer of brightness discrimination in "split-brain" cats. Science, 1960, 132, 734-735.

Myers, R. E., \& Sperry, R. W. Interocular transfer of a visual form discrimination habit in cats after section of the optic chiasma and corpus callosum. Anat. Rec., 1953, 115, 351.

Riesen, A. H., \& Mellinger, J. C. Interocular transfer of habits in cats after alternating monocular visual experience. $J$. comp. physiol. Psychol., 1956, 49, 516-520.

Riesen, A. H., Kurke, M. I., \& Mellinger, J. C. Interocular transfer of habits learned monocularly in visually naive and visually experienced cats. J. comp. physiol. Psychol., 1953, 46, 166-172.

Sperry, R. W., Stamm, J. S., \& Miner, N. Relearning tests for interocular transfer following division of optic chiasma and corpus callosum in cats. $J$, comp. physiol. Psychol., 1956, 49, 529-533.

\section{Notes}

1. This article is based upon a thesis submitted by the senior author in partial fulfillment of the requirements for the $M$. S. degree at Auburn University. Preparation of this article was supported in part by a grant from the Auburn Research Foundation and by USPHS Training Grant No. MH-8565 to the University of Minnesota. The authors wish to thank W. D. Spears, S. C. McIntyre, and R. D. Whiteford for their helpful suggestions in the planning and execution of this study.

2. Now at the Departments of Pharmacology and Psychiatry \& Neurology, University of Minnesota. 